\title{
Effect of Specific Mechanical Energy on In-Vitro Digestion and Physical Properties of Extruded Rice-Based Snacks
}

\author{
Yiming Feng, Youngsoo Lee \\ Department of Food Science and Human Nutrition, University of Illinois Urbana-Champaign, Urbana, USA \\ Email: leeys@illinois.edu
}

Received 26 July 2014; revised 25 August 2014; accepted 3 September 2014

Copyright (C) 2014 by authors and Scientific Research Publishing Inc.

This work is licensed under the Creative Commons Attribution International License (CC BY). http://creativecommons.org/licenses/by/4.0/

(c) (i) Open Access

\begin{abstract}
The effect of specific mechanical energy (SME) on in-vitro digestion and physical properties of extruded rice-based snacks was investigated in this study. Whole grains of medium grain brown rice (BR), medium grain sushi rice (SR) and long grain jasmine rice (JR) were extruded to prepare the rice-based snacks using a single screw extruder without additional thermal energy input. SME during extrusion was varied by changing feed moisture content. The feed moisture content (wet basis) was $9.99 \%-12.55 \%$ for BR, $11.37 \%-13.92 \%$ for SR and $12.42 \%-14.39 \%$ for JR, respectively. Six extruded samples of each type of rice with different SME were collected and analyzed. With the decreasing SME, all three types of rice-based snacks showed significant decreases $(p<0.05)$ on rapidly digestible starch (RDS) and significant increases $(p<0.05)$ on slowly digestible starch (SDS). Physical properties, including expansion ratio (ER), bulk density (BD) and fracture energy (FE) were found to be highly correlated to SME. The results indicated that SME has significant effects on in-vitro digestibility and potentially glycemic index of extruded rice snacks. SME also can be an indicative parameter for the physical properties of rice-based extruded snacks.
\end{abstract}

\section{Keywords}

Extrusion, SME, Rice, Glycemic Index, Degree of Gelatinization, Physical Properties

\section{Introduction}

Extrusion cooking is a continuous process commonly used in industry to produce snacks, breakfast cereal and pet foods [1]. It is considered as a high-temperature and short-time cooking process. Many order-disorder transitions take place during extrusion, such as starch gelatinization and dextrinization, protein denaturation, and complex formation between lipids and amylose [2]. These complex physical and chemical transitions depend on 
processing variables. The processing variables including screw profile and rotating speed, barrel temperature profile, feed rate and composition of the material being extruded have significant effects on the product characteristics [1] [3].

Expanded starch-based foods are considered as high-energy and low-nutrient dense foods, which raises blood sugar rapidly after consumption and are termed as "high glycemic foods" [4] [5]. High glycemic foods elevate blood glucose thereby increasing insulin responses rapidly. Frequent consumption of high glycemic foods is associated with increasing risk of Type II diabetes, obesity and cardiovascular diseases [6] [7]. Glycemic index (GI) of starch-based food has been reported to be affected by many factors such as botanical source of starch, degree of starch gelatinization, types of native crystalline structures, amylose to amylopectin ratio, average molecular weight and complex formation between starch and protein or lipid [6] [8]-[12].

Processing conditions in anextrusion process also have significant effects on physiological properties of the products. Extreme extrusion conditions (low-moisture, high-temperature and high-shear) cause extensive starch gelatinization and dextrinization as well as the destruction of other nutrients. High degree of starch gelatinization and dextrinization lead to increased susceptibility of starch to enzymes and high glycemic index (GI) [2] [13]. Mild extrusion conditions (high moisture content, low residence time and low temperature) would favor higher retention of nutrients [14], which also is capable of producing expanded foods with potentially lower glycemic index.

Specific mechanical energy (SME) has been proposed to establish the relationship between processing variables and properties of expanded products such as density, expansion ratio, solubility and degree of gelatinization [3] [13] [15]. As a system parameter, SME represents the amount of mechanical energy transferred to the feed material during extrusion, and it can be used to indicate extrusion conditions. SME was found to be dependent on feed moisture, feed rate, screw speed and barrel temperature [3]. In general, feed moisture content is the most significant factor affecting the amount of SME [16]. Li and others [17] reported that SME alone cannot be used to predict thermal-mechanical modification in a conventional extruder because additional thermal energy input (i.e. external heating) should also be considered. However, SME has the potential to predict the properties of extruded products when there is no additional thermal energy input.

Rice has become an attractive ingredient in the extrusion industry in recent years because of its neutral taste and white color [18] [19]. It has been proposed that rice has a wide range of glycemic index (GI) depending on varieties and types [20]. Brown rice has been reported to have a significantly lower glycemic index than white rice because of the rich fiber content [21] [22]. In general, rice with higher amylose content tends to have lower glycemic index (GI) than rice with lower amylose content, which is due to starch crystalline type. Amylose has a tendency to form type-B crystalline in starch, and type-B crystalline type was considered to be resistant to $\alpha$-amylase [12] [23]. Conflicting results had also been reported indicating that amylose content alone was not a good predictor of starch digestion rate [24]. A comparison of digestive properties of extruded snacks is produced by different types of rice has not been studied. In addition, the effect of the system parameter, SME, on the glycemic behavior of products is still unknown. The objective of this research is to investigate the relationship between SME and extruded rice properties such as glycemic behaviors, degree of gelatinization and physical properties. The relationship between SME and the digestive and physical properties of extruded rice-based snacks was studied using medium grain brown rice (BR), medium grain sushi rice (SR), and long grain jasmine rice (JR).

\section{Materials and Methods}

\subsection{Raw Materials}

All rice was purchased from a local grocery store. The types of rice that used in this study were medium grain brown rice (BR) (CJ, Los Angeles, CA, USA), medium grain white sushi rice (SR) (CJ, Los Angeles, CA, USA), and long grain jasmine rice (JR) (Three Elephants, Thailand).

\subsection{Extrusion}

Extrusion process was performed using a single screw extruder (Welly puffing machine S2, Jain Inc., South Korea). Screw dimension was $118.9 \times 33.6$ (Lengthxdiameter, $\mathrm{mm}$ ), barrel diameter was $41.2 \mathrm{~mm}$ and die diameter was $3.4 \mathrm{~mm}$. For all extrusion processes, screw speed was set at $120 \mathrm{rpm}$. Barrel temperature during ex- 
trusion varied from $88^{\circ} \mathrm{C}$ to $130^{\circ} \mathrm{C}$ depending on the types of rice and feed moisture content. There was no external heating applied. DI water was pumped into the extruder by the varying rate $(0 \mathrm{~g} / \mathrm{min}-3.13 \mathrm{~g} / \mathrm{min})$ (FMI "Q" Pump Model QG50, Fluid Metering Inc., Syosset, USA) to control the feed moisture content. All types of rice were fed at the feed rate range of $61.6 \mathrm{~g} / \mathrm{min}-65.51 \mathrm{~g} / \mathrm{min}$ with varying feed moisture content between $9.9 \%$ and $14.39 \%$ (wet basis). The feed rate was calculated as the sum of rice feed rate and water pumping rate. The extrudate was cut using a cutting blade rotating at $240 \mathrm{rpm}$. The extrudate was collected in air tight glass jars and stored at room temperature for further analyses.

\subsection{Specific Mechanical Energy (SME)}

Power consumption during the extrusion was measured by a Three-Phase Power Logger (Model 1735, Fluke Corp., Everett, WA). The power consumption is measured directly by the power logger instead of calculating from \%torque, rated power and screw speed. SME was calculated using Equation (1). In this Equation, empty power was measured by the power logger when running the extruder without feeding the rice. Loading power was measured when running during feeding. Power consumptions were recorded every 2 seconds for 2 minutes and the average values during the extrusion were used to calculate SME.

$$
\operatorname{SME}(\mathrm{kJ} / \mathrm{kg})=\frac{\text { loading power }(\mathrm{kJ} / \mathrm{s})-\text { empty power }(\mathrm{kJ} / \mathrm{s})}{\text { feed rate }(\mathrm{kg} / \mathrm{s})}
$$

\subsection{Texture Analysis}

Two pieces of the extruded samples were weighed and placed on a TA-XT2i texture analyzer (Texture Technologies Corp., Scarsdale, NY, USA) using a mini Kramer shear press (TA-91M). The test speed was $1 \mathrm{~mm} / \mathrm{s}$ and the shear press traveled $100 \%$ of the sample's diameter. The area under force $(\mathrm{N})$ vs. distance $(\mathrm{mm})$ curve represents the energy required to break a sample, which can be translated to the hardness of the sample [16]. The breaking energy divided by the mass of the sample represents the fracture energy (FE) per unit mass.

\subsection{Bulk Density and Expansion Ratio}

Each extruded sample was placed to fill a $200 \mathrm{ml}$ cylinder to measure bulk density. Bulk density was calculated as weight (g) per unit volume (ml). Expansion ratio is the ratio of the extrudate's cross-sectional area to the extruder die orifice cross-sectional area. The diameters used for calculating cross-sectional area were measured using a caliper (Mecanic Type 6911, Manostat Corp., Woodstock, NY).

\subsection{Degree of Gelatinization}

Degree of gelatinization was measured by modified Wootton's method [9]. The extruded sample $(1 \mathrm{~g})$ was ground using a grinder (CBM-18, Cuisinart, East Windsor, NJ) and screened by No. 45 US sieve. The portion of particle size less than $355 \mu \mathrm{m}$ was collected and used. The ground sample (1 g) was dispersed in $50 \mathrm{ml}$ DI water for $30 \mathrm{~min}$ with stirring speed at $300 \mathrm{rpm}$. The suspension was then centrifuged (MiniSpin Plus, Eppendorf, Germany) at $8000 \mathrm{~g}$ for $10 \mathrm{~min}$ at room temperature. Duplicate of $1 \mathrm{ml}$ supernatant was taken and mixed with $8.9 \mathrm{ml}$ DI water and $0.1 \mathrm{ml}$ iodine solution containing $4 \% \mathrm{KI}$ and $1 \% \mathrm{I}_{2}$. Absorbance $\left(\mathrm{A}_{1}\right)$ was measured at 600 $\mathrm{nm}$ against blank. Ground raw rice $(1 \mathrm{~g})$ in duplicate was mixed with $20 \mathrm{ml}$ DI water ( $5 \% \mathrm{w} / \mathrm{v})$ and boiled for 50 min. The solution was then cooled down to room temperature and the final volume was adjusted to $50 \mathrm{ml}$ using DI water. The mixture was dispersed evenly by constant stirring for 30 min at speed $300 \mathrm{rpm}$ and then centrifuged for $10 \mathrm{~min}$ at $8000 \mathrm{~g}$. The supernatant was then diluted and treated with the iodine solution and the absorbance was measured at $600 \mathrm{~nm}\left(\mathrm{~A}_{2}\right)$ as described above. Degree of gelatinization (DG\%) was calculated using the following Equation (2).

$$
\mathrm{DG} \%=\left(\mathrm{A}_{1} / \mathrm{A}_{2}\right) * 100
$$

\subsection{In-Vitro Glycemic Behavior}

An in-vitro glycemic behavior was tested using modified Englyst’s [25] method. In gastric phase, $100 \mathrm{mg}( \pm 10$ 
mg) extruded sample was incubated with $10 \mathrm{ml}$ pepsin (P7000, Sigma-Aldrich, St. Louis, MO) solution (5 g/L pepsin dissolved in $0.01 \mathrm{M} \mathrm{HCl}), 5 \mathrm{~g} / \mathrm{L}$ guar gum and 5 glass beads $(\mathrm{d}=5 \mathrm{~mm})$ at $37^{\circ} \mathrm{C}$ with shaking at $250 \mathrm{rpm}$ for $30 \mathrm{~min}$. $\mathrm{pH}$ was then adjusted to 5.8 using $5 \mathrm{ml} 0.25 \mathrm{M}$ sodium acetate buffer. $3 \mathrm{~mL}$ mixture of pancreatin (4 g/L) (P1750, Sigma-Aldrich, St. Louise, MO) and amyloglucosidase (22.2 unit/ml) (A7095, Sigma-Aldrich, St. Louise, MO) solution was added to start the intestinal phase. After 20 min of incubation in the intestinal phase, $0.2 \mathrm{ml}$ sample was taken and immediately placed into $1.8 \mathrm{ml}$ of $99.5 \%$ ethanol (Sigma-Aldrich, St. Louise, MO., USA) to inactivate enzymes. The sample and ethanol mixture was then centrifuged at $4696 \mathrm{~g}$ for $20 \mathrm{~min}$ at $-10^{\circ} \mathrm{C}$ (SorvallST16R, Thermo Fisher Scientific Inc., USA). $0.1 \mathrm{ml}$ of the supernatant was taken to determine the glucose concentration $\left(\mathrm{G}_{20}\right)$ using Glucose kit GAGO-20 (Sigma-Aldrich, St. Louise, MO). Another sample was taken at 120 min after intestinal incubation and the glucose concentration $\left(\mathrm{G}_{120}\right)$ was determined using the same procedure for $\mathrm{G}_{20}$. $\mathrm{G}_{20}$ was measured as the total amount of glucose released after intestinal incubation for 20 minutes. $G_{120}$ was also measured as the total amount of glucose released after intestinal incubation for 120 minutes. Rapidly digestible starch (RDS) is calculated by Equation (3) and slowly digestible starch (SDS) is described as Equation (4) [26].

$$
\begin{aligned}
& \mathrm{RDS}=\mathrm{G}_{20} * 0.9 \\
& \mathrm{SDS}=0.9 *\left(\mathrm{G}_{120}-\mathrm{G}_{20}\right)
\end{aligned}
$$

\subsection{Statistical Analysis}

The collected data were analyzed using analysis of variance (ANOVA) and least significant differences (LSD) (Version 9.4, SAS Institute, Cary, NC). Results with a corresponding probability value of p $<0.05$ were considered to be significantly different.

\section{Results and Discussion}

\subsection{Specific Mechanical Energy (SME) and Feed Moisture Content}

Specific mechanical energy (SME) during extrusion was inversely correlated with feed moisture content (Figure 1) due to viscosity change via adding water [16] [27]. In an extrusion process, SME is a function of many variables such as screw speed and rheological properties of feeding materials. At a given feed rate of dry material, SME decreases with the increasing feed moisture for all samples because water worked as a lubricant and reduced the viscosity of the feed melt in the extruder. SME also differs from different types of rice due to their varied compositions. At given feed moisture content, long grain jasmine rice (JR) has a higher SME value than brown rice (BR) and sushi rice (SR). Long grain rice generally contains higher amylose content than medium grain rice such as brown rice (BR) and sushi rice (SR) [28]. Viscosity of starchy material can increase due to the release of amylose upon heating [29]. Since jasmine rice (JR) contains higher amylose content, the melt might be more viscous during extrusion and eventually requires higher SME than brown rice (BR) and sushi rice (SR). Brown rice (BR) and sushi rice (SR) are both from the same botanical source but differ in degree of milling [30]. Milling process removes bran layer where the majority of lipid in rice exists [31]. During an extrusion process, lipid also works as a lubricant that decreases SME. As a result, the brown rice (BR), with lower degree of milling than the sushi rice (SR), required slightly less SME than the sushi rice (SR) at the same feed moisture as shown in Figure 1.

\subsection{Starch Gelatinization}

For all three types of rice, starch gelatinization and SME increased with the reduction of feed moisture content (Table 1). This result is consistent with the results reported in previous studies [13] [17] [32]. In an extruder, part of the mechanical energy input is converted to thermal energy through mechanical shearing. With more SME input, the more energy will be converted to thermal energy and therefore a higher die temperature can be reached. In the past studies, degree of gelatinization (DG\%) has been reported to be proportional to die temperature [33]. In this study, DG\% was also found to be positively related to die temperature (data not shown).

In an extrusion process, destruction of starch structure and gelatinization of starch are achieved by both thermal cooking and physical shearing [2] [34] [35]. In this study, higher SME indicated higher degree of mechanical 


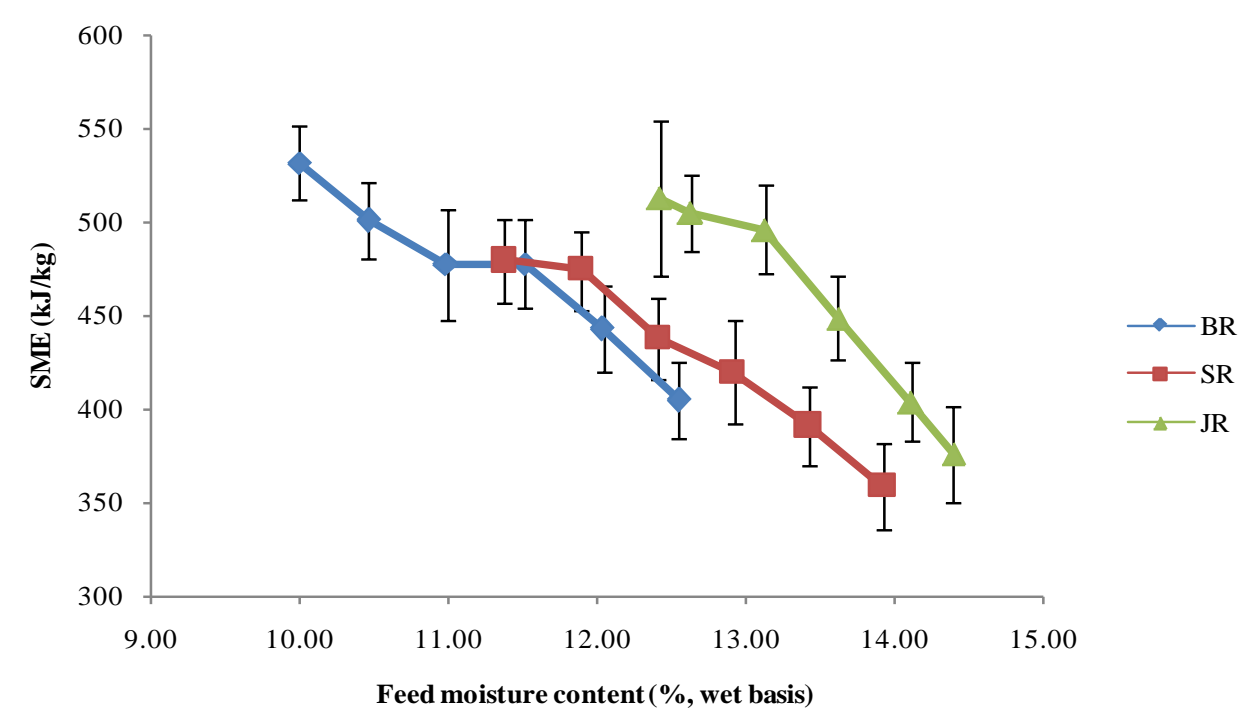

Figure 1. Effect of feed moisture content on specific mechanical energy (SME) for medium grain brown rice (BR), medium grain sushi rice (SR) and long grain jasmine rice (JR). Screw speed 120 rpm; Dry feed rate BR $61.6 \mathrm{~g} / \mathrm{min}$, SR $61.5 \mathrm{~g} / \mathrm{min}$ and JR $62.6 \mathrm{~g} / \mathrm{min}$.

Table 1. Effect of feed moisture content and specific mechanical energy (SME) on the properties of the product.

\begin{tabular}{|c|c|c|c|c|c|c|c|}
\hline $\begin{array}{l}\text { Moisture content } \\
\text { (\%) }\end{array}$ & $\begin{array}{l}\mathrm{SME} \\
(\mathrm{kJ} / \mathrm{kg})\end{array}$ & $\begin{array}{c}\text { Degree of gelatinization } \\
(\%)\end{array}$ & RDS (g) & SDS (g) & $\begin{array}{l}\text { Fracture energy } \\
(\mathrm{mJ} / \mathrm{g})\end{array}$ & Expansion ratio & $\begin{array}{l}\text { Bulk density } \\
\left(\mathrm{g} / \mathrm{cm}^{3}\right)\end{array}$ \\
\hline \multicolumn{8}{|l|}{$\mathrm{BR}$} \\
\hline 9.99 & 531.34a & $60.80 \mathrm{a}$ & $37.77 \mathrm{a}$ & $3.45 b$ & $1009.9 \mathrm{e}$ & $10.05 a$ & $0.065 f$ \\
\hline 10.46 & $500.62 b$ & $58.92 a$ & 37.36ab & $5.29 b$ & 1173.9d & $9.56 \mathrm{ab}$ & $0.072 \mathrm{e}$ \\
\hline 10.99 & $477.93 c$ & $57.58 \mathrm{a}$ & 31.87ab & 14.41ab & $1187.8 \mathrm{~cd}$ & $8.94 \mathrm{bc}$ & $0.088 \mathrm{~d}$ \\
\hline 11.51 & $477.03 c$ & $51.03 \mathrm{~b}$ & 30.93ab & 11.71ab & $1338.2 \mathrm{c}$ & $8.74 \mathrm{c}$ & $0.101 \mathrm{c}$ \\
\hline 12.03 & $442.52 d$ & $45.17 \mathrm{c}$ & $25.48 \mathrm{bc}$ & 13.50ab & $1844.1 \mathrm{~b}$ & $7.26 \mathrm{~d}$ & $0.130 \mathrm{~b}$ \\
\hline 12.55 & $404.53 \mathrm{e}$ & $44.68 c$ & $17.92 \mathrm{c}$ & $23.82 a$ & 2113.1a & $6.56 \mathrm{e}$ & $0.160 \mathrm{a}$ \\
\hline \multicolumn{8}{|l|}{ SR } \\
\hline 11.37 & 479.41a & 58.19a & $32.22 \mathrm{a}$ & $14.65 \mathrm{bc}$ & 886.9e & $9.51 \mathrm{a}$ & $0.113 \mathrm{~d}$ \\
\hline 11.89 & $474.39 a$ & $57.54 a$ & $35.30 \mathrm{a}$ & $12.50 \mathrm{c}$ & 1045.3de & $9.12 \mathrm{ab}$ & $0.116 \mathrm{~d}$ \\
\hline 12.41 & 437.99b & $57.38 \mathrm{a}$ & 29.58ab & $20.85 a b c$ & $1267.7 \mathrm{~cd}$ & $8.55 b$ & $0.137 \mathrm{c}$ \\
\hline 12.91 & 419.86c & $56.70 \mathrm{ab}$ & 31.82ab & $15.47 \mathrm{bc}$ & $1404.7 \mathrm{c}$ & 7.77c & $0.145 \mathrm{c}$ \\
\hline 13.42 & 391.06d & 52.94ab & $19.24 \mathrm{c}$ & $28.09 a$ & $1798.8 b$ & $6.73 d$ & $0.165 b$ \\
\hline 13.92 & 359.02e & $48.42 \mathrm{~b}$ & $22.44 \mathrm{bc}$ & $24.40 \mathrm{ab}$ & 2162.2a & $5.54 \mathrm{e}$ & $0.199 a$ \\
\hline \multicolumn{8}{|l|}{$\mathrm{JR}$} \\
\hline 12.42 & 512.61a & $57.03 a$ & $39.05 a$ & $2.59 \mathrm{~b}$ & $802.0 \mathrm{~d}$ & $9.27 \mathrm{a}$ & $0.105 \mathrm{~d}$ \\
\hline 12.62 & $504.80 \mathrm{ab}$ & $57.35 a$ & 37.13a & $0.48 \mathrm{~b}$ & $1062.4 \mathrm{c}$ & $8.48 b$ & $0.114 \mathrm{~d}$ \\
\hline 13.12 & 495.95b & $56.43 \mathrm{~b}$ & $35.95 a$ & $8.74 a b$ & 1248.1b & $8.22 b$ & $0.129 \mathrm{c}$ \\
\hline 13.62 & $448.46 c$ & $53.34 \mathrm{c}$ & 30.33ab & $15.53 a$ & $1305.5 \mathrm{ab}$ & $6.53 c$ & $0.150 \mathrm{~b}$ \\
\hline 14.10 & $404.00 \mathrm{~d}$ & $51.92 \mathrm{~d}$ & $25.85 b$ & $13.34 a$ & 1315.9ab & $5.68 \mathrm{~d}$ & $0.172 \mathrm{a}$ \\
\hline 14.39 & $375.64 \mathrm{e}$ & $44.35 \mathrm{e}$ & $23.08 \mathrm{~b}$ & 15.13a & 1395.27a & $5.66 \mathrm{~d}$ & $0.174 a$ \\
\hline
\end{tabular}

Means with the same letters in the same column within each rice type are not significantly different at $\alpha=0.05$. BR $=$ medium grain brown rice, SR $=$ medium grain sushi rice and $\mathrm{JR}=$ long grain jasmine rice. 
shearing on starch granules, which resulted in higher DG\%. The DG\% value of the samples produced by this short-screw extruder was lower than the reported DG\% of products processed by other extruders possibly due to reduced residence-time of the short-screw extruder [34]. Previous studies reported that starch-based foods with lower DG\% are likely to cause less glycemic response during digestion because gelatinization makes starch susceptible to enzymatic reactions [8] [12] [36]. Therefore, decreasing DG\% can contribute to lower glycemic index, which can be controlled by extrusion process parameters.

\subsection{In-Vitro Glycemic Behavior}

Estimating glycemic index (GI) using in-vivo experiments is a time consuming process and the GI results could be affected by the health conditions and the age of panelists. Several approaches have been developed to predict GI using in-vitro methods, which are economical, convenient, and more likely to produce objective results [5] [26] [35]. According to Englyst et al. [37], starch can be classified to three categories based on digestibility: rapidly digestible starch (RDS), slowly digestible starch (SDS) and resistant starch (RS). Rapidly digestible starch (RDS) has been used to characterize in-vivo glycemic index (GI) due to a positive correlation between the two [23] [37]. Slowly digestible starch (SDS) has been proposed to exhibit many health benefits such as a slow increase of postprandial blood glucose, good stability and sustainability of blood glucose level, mild hormonal responses and desirable satiety and diabetes management [38] [39]. Previous studies made efforts to lower glycemic potential through re-formulation such asprotein fortification [4] and chemical modification of starch to increase the amount of resistant starch (RS) and slowly digestible starch (SDS) in native starch [26] [39].

As the results presented in Table 1, across all types of rice, a significant decrease of rapidly digestible starch (RDS) was observed when decreasing SME gradually through the control of feed moisture content. In contrast, the amount of slowly digestible starch (SDS) increased with decreasing SME. This was attributed partially to the decreased degree of gelatinization as less SME was applied during the extrusion processes. Figure 2 illustrates the correlation between DG\% and RDS or SDS as well as SME and RDS or SDS. The coefficient of determination values $\left(\mathrm{R}^{2}\right)$ for SME vs. RDS and SDS (Figures 2(d)-(f)) were greater than those for DG\% vs. RDS and SDS (Figures 2(a)-(c)). These results suggested that RDS and SDS may be better correlated to SME than DG\%. In previous studies, only DG\% has been correlated to in-vitro glycemic index (GI) because of the difficulty of quantifying starch dextrinization [8]. However, the results shown in Figure 2 indicate that DG\% may not be a proper indicator to predict in-vitro GI because the effect of dextrinization is also indispensable in an extrusion process. Dextrinization is a fragmentation of starch molecules caused by physical shearing. During extrusion, the degree of dextrinization was observed to be positively correlated to shear-speed and negatively correlated to feed moisture content [2]. The relationship of increased SME during an extrusion process and decreased average molecular weight in the extrudate has been reported [40]. Starch molecules with less molecular weight and shorter chain length were proved to be more susceptible to enzymatic digestion [2] [12]. Therefore SME, as a parameter to include the combined effect of both gelatinization and dextrinization, is preferred than DG\% to predict the digestive properties of starch-based extruded foods. The total amount of digestible starch (RDS + SDS) does not change with SME or DG\% at $\mathrm{p}=0.05$.

Comparing medium grain brown rice (BR), medium grain sushi rice (SR) and long grain jasmine rice (JR), there were no significant differences regarding RDS and SDS although they are different in composition. JR contains $15 \%$ amylose [41], which is slightly higher than medium grain BR (13.8\%) and medium grain SR (14.2\%) [42]. BR contains higher fat, protein and fiber content than SR [31]. However, in this study, JR and SR exhibited similar RDS and SDS, because their differences in composition may not be significant enough, especially for the amylose to amylopectin ratio when comparing to other starch sources such as waxy rice. Brown rice has been considered as low GI rice because it contains higher fat, protein and fiber content than white rice. Those components could help to form a protective structure to inhibit starch granules from diffusion by hydrolytic enzymes [39] [43]. However, extrusion is an extreme process with high temperature and extensive shearing, which does not allow the formation protective structures. Therefore, extruded brown rice exhibited similar invitro glycemic behavior compared to white rice such as SR.

\subsection{Physical Properties}

Data in Table 1 show that physical properties change significantly with feed moisture content and specific mechanical energy (SME). The equations and $\mathrm{R}^{2}$ values using linear regressions between SME and physical 

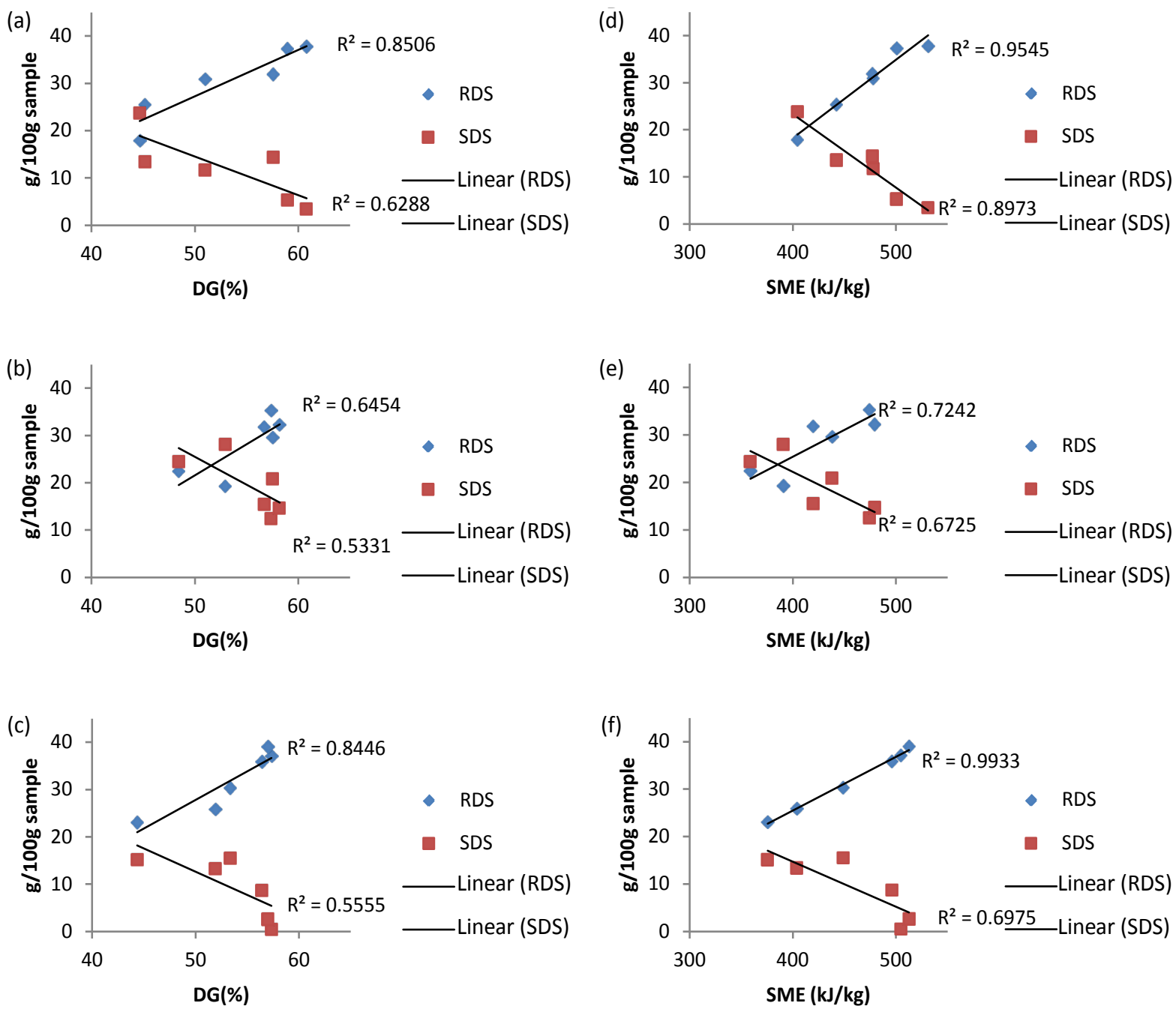

Figure 2. Rapidly digestible starch (RDS) and slowly digestible starch (SDS) as a function of degree of gelatinization (DG\%) and specific mechanical energy (SME) for medium grain brown rice (BR), medium grain sushi rice (SR) and long grain jasmine rice (JR). (a) BR: RDS, SDS vs. DG\%; (b) SR: RDS, SDS vs. DG\%; (c) JR: RDS, SDS vs. DG\%; (d) BR: RDS, SDS vs. SME; (e) SR: RDS, SDS vs. SME; (f) JR: RDS, SDS vs. SME.

properties are shown in Table 2. Expansion ratio is positively correlated to SME while fracture energy and bulk density are negatively correlated. The results are consistent to a previous study [16]. Overall, the physical properties of the rice products produced using this single-variable extrusion process were explained by SME alone. Onwulata et al. (1994) proposed that bulk density of extruded corn meal can be characterized adequately by SME in a twin-screw extrusion process. However, only three data points has been used to build the Equation between specific volume (bulk density) and SME [3]. In this study, more physical properties of extrudates were analyzed and more data points (six) were measured to improve the accuracy of regression equations.

\section{Conclusion}

In an extrusion process without additional thermal energy input, SME as a system parameter could work as a good indicator of many properties of extrudates such as physical and digestive properties. Medium grain brown rice (BR), medium grain shush rice (SR) and long grain jasmine rice (JR) were used as raw material to study the relationship between SME and properties of extrudates. Reducing SME input during extrusion was found to significantly reduce the amount of rapidly digestible starch (RDS) in the products, and increase the amount of slowly digestible starch (SDS). The physical properties including fracture energy, expansion ratio and bulk density 
Table 2. Fitted Equations using SME and $\mathrm{R}^{2}$ statistics for physical properties.

\begin{tabular}{ccc}
\hline Physical Properties & Fitted Equation & $R^{2}$ \\
Medium grain brown rice & & 0.912 \\
FE $(\mathrm{mJ} / \mathrm{g})$ & $\mathrm{FE}=-9.3809 \mathrm{X}+5874.9$ & 0.967 \\
$\mathrm{ER}$ & $\mathrm{ER}=0.0299 \mathrm{X}-5.60$ & 0.956 \\
BD $\left(\mathrm{g} / \mathrm{cm}^{3}\right)$ & $\mathrm{BD}=-0.0008 \mathrm{X}+0.48$ & 0.980 \\
Medium grain sushi rice & & 0.981 \\
FE $(\mathrm{mJ} / \mathrm{g})$ & $\mathrm{FE}=-10.051 \mathrm{X}+5718.9$ & 0.973 \\
$\mathrm{ER}$ & $\mathrm{ER}=0.0318 \mathrm{X}-5.73$ & $\mathrm{BD}=-0.0007 \mathrm{X}+0.461$ \\
$\mathrm{BD}\left(\mathrm{g} / \mathrm{cm}^{3}\right)$ & & \\
Long grain jasmine rice & $\mathrm{FE}=-3.6967 \mathrm{X}+2824.2$ & 0.831 \\
$\mathrm{FE}(\mathrm{mJ} / \mathrm{g})$ & $\mathrm{ER}=0.0261 \mathrm{X}-4.61$ & 0.928 \\
$\mathrm{ER}$ & $\mathrm{BD}=-0.0005 \mathrm{X}+0.35$ & 0.921 \\
\hline
\end{tabular}

${ }^{*} \mathrm{X}=\mathrm{SME}(\mathrm{kJ} / \mathrm{kg}) ; \mathrm{FE}=$ fracture energy $(\mathrm{mJ} / \mathrm{g}) ; \mathrm{ER}$ = expansion ratio; BD = bulk density $\left(\mathrm{g} / \mathrm{cm}^{3}\right)$.

could be characterized by SME. Further study could be conducted by incorporating more processing variables such as screw speed and residence time.

\section{Acknowledgements}

The authors acknowledge the support from Dr. Juan Andrade and Mr. Brian Jacobson.

\section{References}

[1] Ilo, S., Tomschik, U., Berghofer, E. and Mundigler, N. (1996) The Effect of Extrusion Operating Conditions on the Apparent Viscosity and the Properties of Extrudates in Twin-Screw Extrusion Cooking of Maize Grits. Food Science \& Technology, 29, 593-598. http://dx.doi.org/10.1006/fstl.1996.0092

[2] Lai, L.S. and Kokini, J.L. (1991) Physicochemical Changes and Rheological Properties of Starch during Extrusion. (A Review). Biotechnology progress, 7, 251-266. http://dx.doi.org/10.1021/bp00009a009

[3] Onwulata, C.I., Mulvaney, S.J. and Hsieh, F. (1994) System Analysis as the Basis for Control of Density of Extruded Cornmeal. Food Control, 5, 39-48. http://dx.doi.org/10.1016/0956-7135(94)90132-5

[4] Onwulata, C.I., Thomas, A.E., Cooke, P.H., Phillips, J.H., Carvalho, C.W.P., Ascheri, J.L.R. and Tomasula, P.M. (2010) Glycemic Potential of Extruded Barley, Cassava, Corn, and Quinoa Enriched with Whey Proteins and Cashew Pulp. International Journal of Food Properties, 13, 338-359. http://dx.doi.org/10.1080/10942910802398487

[5] Englyst, K.N., Vinoy, S., Englyst, H.N. and Lang, V. (2003) Glycaemic Index of Cereal Products Explained by Their Content of Rapidly and Slowly Available Glucose. British Journal of Nutrition, 89, 329-339. http://dx.doi.org/10.1079/BJN2002786

[6] Ludwig, D.S. (2002) The Glycemic Index. JAMA: The Journal of the American Medical Association, 287, $2414-2423$. http://dx.doi.org/10.1001/jama.287.18.2414

[7] Englyst, K.N., Englyst, H.N., Hudson, G.J., Cole, T.J. and Cummings, J.H. (1999) Rapidly Available Glucose in Foods: An in Vitro Measurement That Reflects the Glycemic Response. The American Journal of Clinical Nutrition, 69, 448-454.

[8] Parada, J. and Aguilera, J.M. (2009) In Vitro Digestibility and Glycemic Response of Potato Starch Is Related to Granule Size and Degree of Gelatinization. Journal of Food Science, 74, E34-E38. http://dx.doi.org/10.1111/j.1750-3841.2008.01016.x

[9] Wootton, M. and Chaudhry, M.A. (1980) Gelatinization and in Vitro Digestibility of Starch in Baked Products. Journal of Food Science, 45, 1783-1784. http://dx.doi.org/10.1111/j.1365-2621.1980.tb07613.x

[10] Parada, J. and Aguilera, J.M. (2012) Effect of Native Crystalline Structure of Isolated Potato Starch on Gelatinization 
Behavior and Consequently on Glycemic Response. Food Research International, 45, 238-243. http://dx.doi.org/10.1016/j.foodres.2011.10.042

[11] Hallfrisch, J. and Behall, K.M. (2000) Mechanisms of the Effects of Grains on Insulin and Glucose Responses. Journal of the American College of Nutrition, 19, 320S-325S. http://dx.doi.org/10.1080/07315724.2000.10718967

[12] Parada, J. and Aguilera, J.M. (2011) Review: Starch Matrices and the Glycemic Response. Food Science and Technology International, 17, 187-204. http://dx.doi.org/10.1177/1082013210387712

[13] Yeh, A.I. and Jaw, Y.M. (1999) Effects of Feed Rate and Screw Speed on Operating Characteristics and Extrudate Properties during Single-Screw Extrusion Cooking of Rice Flour. Cereal Chemistry, 76, 236-242. http://dx.doi.org/10.1094/CCHEM.1999.76.2.236

[14] Singh, S., Gamlath, S. and Wakeling, L. (2007) Nutritional Aspects of Food Extrusion: A Review. International Journal of Food Science \& Technology, 42, 916-929. http://dx.doi.org/10.1111/j.1365-2621.2006.01309.x

[15] Kumar, A., Ganjyal, G.M., Jones, D.D. and Hanna, M.A. (2007) Experimental Determination of Longitudinal Expansion during Extrusion of Starches. Cereal Chemistry, 84, 480-484. http://dx.doi.org/10.1094/CCHEM-84-5-0480

[16] Ding, Q.B., Ainsworth, P., Plunkett, A., Tucker, G. and Marson, H. (2006) The Effect of Extrusion Conditions on the Functional and Physical Properties of Wheat-Based Expanded Snacks. Journal of Food Engineering, 73, 142-148. http://dx.doi.org/10.1016/j.jfoodeng.2005.01.013

[17] Li, P.X., Campanella, O.H. and Hardacre, A.K. (2004) Using an In-Line Slit-Die Viscometer to Study the Effects of Extrusion Parameters on Corn Melt Rheology. Cereal Chemistry, 81, 70-76. http://dx.doi.org/10.1094/CCHEM.2004.81.1.70

[18] Kadan, R.S., Bryant, R.J. and Pepperman, A.B. (2003) Functional Properties of Extruded Rice Flours. Journal of Food Science, 68, 1669-1672. http://dx.doi.org/10.1111/j.1365-2621.2003.tb12311.x

[19] Chaiyakul, S., Jangchud, K., Jangchud, A., Wuttijumnong, P. and Winger, R (2009) Effect of Extrusion Conditions on Physical and Chemical Properties of High Protein Glutinous Rice-Based Snack. Food Science \& Technology, 42, 781787.

[20] Miller, J.B., Pang, E. and Bramall, L. (1992) Rice: A High or Low Glycemic Index Food? The American Journal of Clinical Nutrition, 56, 1034-1036.

[21] Foster-Powell, K., Holt, S.H. and Brand-Miller, J.C. (2002) International Table of Glycemic Index and Glycemic Load Values: 2002. The American Journal of Clinical Nutrition, 76, 5-56.

[22] Sun, Q., Spiegelman, D., van Dam, R.M., Holmes, M.D., Malik, V.S., Willett, W.C. and Hu, F.B. (2010) White Rice, Brown Rice and Risk of Type 2 Diabetes in US Men and Women. Archives of Internal Medicine, 170, 961-969. http://dx.doi.org/10.1001/archinternmed.2010.109

[23] Zhu, L.J., Liu, Q.Q., Wilson, J.D., Gu, M.H. and Shi, Y.C. (2011) Digestibility and Physicochemical Properties of Rice (Oryza sativa L.) Flours and Starches Differing in Amylose Content. Carbohydrate Polymers, 86, 1751-1759. http://dx.doi.org/10.1016/j.carbpol.2011.07.017

[24] Panlasigui, L.N., Thompson, L.U., Juliano, B.O., Perez, C.M., Yiu, S.H. and Greenberg, G.R. (1991) Rice Varieties with Similar Amylose Content Differ in Starch Digestibility and Glycemic Response in Humans. The American Journal of Clinical Nutrition, 54, 871-877.

[25] Englyst, H.N., Kingman, S.M. and Cummings, J.H. (1992) Classification and Measurement of Nutritionally Important Starch Fractions. European journal of clinical nutrition, 46, S33-S50.

[26] Sang, Y. and Seib, P.A. (2006) Resistant Starches from Amylose Mutants of Corn by Simultaneous Heat-Moisture Treatment and Phosphorylation. Carbohydrate Polymers, 63, 167-175. http://dx.doi.org/10.1016/j.carbpol.2005.07.022

[27] Baik, B.K., Powers, J. and Nguyen, L.T. (2004) Extrusion of Regular and Waxy Barley Flours for Production of Expanded Cereals. Cereal Chemistry, 81, 94-99. http://dx.doi.org/10.1094/CCHEM.2004.81.1.94

[28] Williams, V.R., Wu, W.T., Tsai, H.Y. and Bates H.G. (1958) Rice Starch, Varietal Differences in Amylose Content of Rice Starch. Journal of Agricultural and Food Chemistry, 6, 47-48. http://dx.doi.org/10.1021/jf60083a009

[29] Yeh, A.Y. and Li, J.Y. (1996) A Continuous Measurement of Swelling of Rice Starch During Heating. Journal of Cereal Science, 23, 277-283. http://dx.doi.org/10.1006/jcrs.1996.0028

[30] Park, J.K., Kim, S.S. and Kim, K.O. (2001) Effect of Milling Ratio on Sensory Properties of Cooked Rice and on Physicochemical Properties of Milled and Cooked Rice. Cereal Chemistry, 78, 151-156. http://dx.doi.org/10.1094/CCHEM.2001.78.2.151

[31] Ohtsubo, K.I., Suzuki, K., Yasui, Y., and Kasumi, T. (2005) Bio-Functional Components in the Processed Pre-Germinated Brown Rice by a Twin-Screw Extruder. Journal of Food Composition and Analysis, 18, 303-316. http://dx.doi.org/10.1016/j.jfca.2004.10.003 
[32] Gropper, M., Moraru, C.I. and Kokini, J.L. (2002) Effect of Specific Mechanical Energy on Properties of Extruded Protein-Starch Mixtures. Cereal Chemistry, 79, 429-433. http://dx.doi.org/10.1094/CCHEM.2002.79.3.429

[33] Seibel, W. and Hu, R. (1994) Gelatinization Characteristics of a Cassava/Corn Starch Based Blend during Extrusion Cooking Employing Response Surface Methodology. Starch-Stärke, 46, 217-224. http://dx.doi.org/10.1002/star.19940460604

[34] Ayoub, A., Liu, Y., Miller, D.D. and Rizvi, S.S (2013) The Effect of Low Shear on the Development of Fortified Extruded Rice Products. Starch-Stärke, 65, 517-526.

[35] François, P.L. (1989) In-Vitro Availability of Starch in Cereal Products. Journal of the Science of Food and Agriculture, 49, 499-501. http://dx.doi.org/10.1002/jsfa.2740490413

[36] Dona, A.C., Pages, G., Gilbert, R.G. and Kuchel, P.W. (2010) Digestion of Starch: In Vivo and in Vitro Kinetic Models Used to Characterise Oligosaccharide or Glucose Release. Carbohydrate Polymers, 80, 599-617. http://dx.doi.org/10.1016/j.carbpol.2010.01.002

[37] Englyst, H.N., Veenstra, J. and Hudson, G.J. (1996) Measurement of Rapidly Available Glucose (RAG) in Plant Foods: A Potential in Vitro Predictor of the Glycaemic Response. British Journal of Nutrition, 75, 327. http://dx.doi.org/10.1079/BJN19960137

[38] Zhang, G. and Hamaker, B.R. (2009) Slowly Digestible Starch: Concept, Mechanism and Proposed Extended Glycemic Index. Critical Reviews in Food Science and Nutrition, 49, 852-867. http://dx.doi.org/10.1080/10408390903372466

[39] Lehmann, U. and Robin, F. (2007) Slowly Digestible Starch-Its Structure and Health Implications: A Review. Trends in Food Science \& Technology, 18, 346-355. http://dx.doi.org/10.1016/j.tifs.2007.02.009

[40] van Lengerich, B. (1990) Influence of Extrusion Processing on In-Line Rheological Behavior, Structure and Function of Wheat Starch. Dough Rheology and Baked Product Texture, Springer US, 421-471.

[41] Khunae, P., Tran, T. and Sirivongpaisal, P. (2007) Effect of Heat-Moisture Treatment on Structural and Thermal Properties of Rice Starches Differing in Amylose Content. Starch-Stärke, 59, 593-599. http://dx.doi.org/10.1002/star.200700618

[42] Champagne, E.T., Richard, O.A., et al. (1996) Quality Evaluation of US Medium-Grain Rice Using a Japanese Taste Analyzer. Cereal chemistry, 73, 290-294.

[43] Colonna, P., Leloup, V. and Buleon, A. (1992) Limiting Factors of Starch Hydrolysis. European Journal of Clinical Nutrition, 46, S17-S32. 
Scientific Research Publishing (SCIRP) is one of the largest Open Access journal publishers. It is currently publishing more than 200 open access, online, peer-reviewed journals covering a wide range of academic disciplines. SCIRP serves the worldwide academic communities and contributes to the progress and application of science with its publication.

Other selected journals from SCIRP are listed as below. Submit your manuscript to us via either submit@scirp.org or Online Submission Portal.
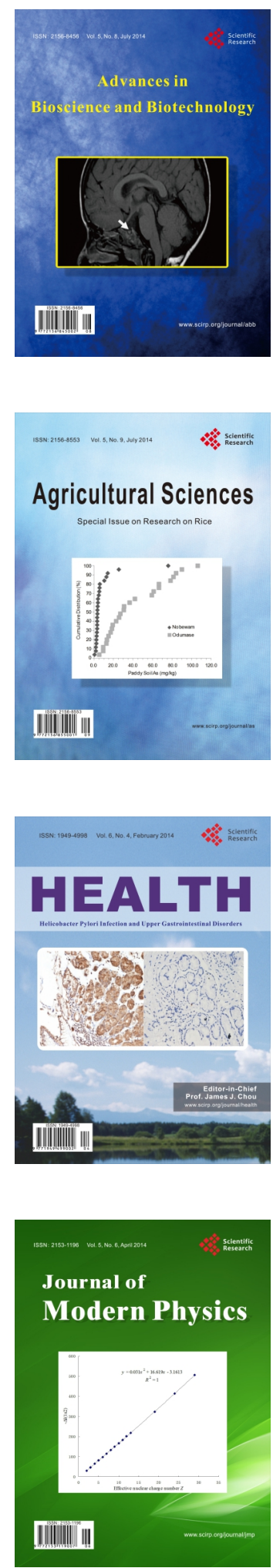
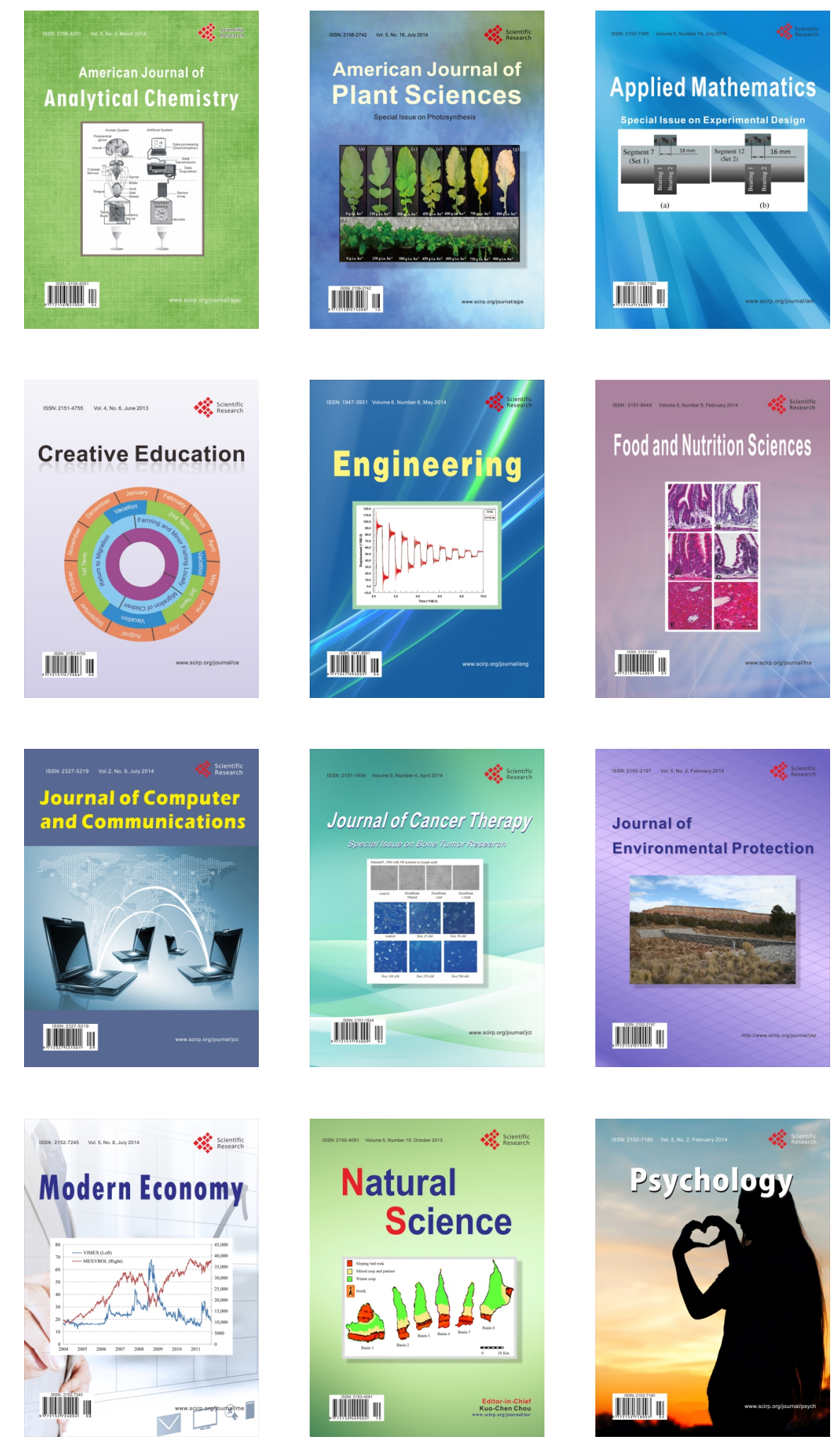